\title{
Article
}

\section{Pilot Model for Community Based Oral Cancer Screening Program: Outcome from 4 Northeastern Provinces in Thailand}

\author{
Boworn Klongnoi ${ }^{1, *}$, Vanvisa Sresumatchai ${ }^{2}{ }^{\circ}$, Siribang-on Piboonniyom Khovidhunkit ${ }^{3}$, \\ Pornpoj Fuangtharnthip ${ }^{3}{ }^{1}$, Rachatawan Leelarungsun ${ }^{3}$ and Binit Shrestha ${ }^{4}$ \\ 1 Department of Oral and Maxillofacial Surgery, Faculty of Dentistry, Mahidol University, 6 Yothi Street \\ Ratchathewi District, Bangkok 10400, Thailand \\ 2 Department of Biostatistics, Faculty of Public Health, Mahidol University, 420/1 Ratchawithi Road, \\ Ratchathewi District, Bangkok 10400, Thailand; vanvisa.sre@mahidol.ac.th \\ 3 Department of Advanced General Dentistry, Faculty of Dentistry, Mahidol University, 6 Yothi Street, \\ Ratchathewi District, Bangkok 10400, Thailand; siribangon.pib@mahidol.ac.th (S.-o.P.K.); \\ pornpoj.fun@mahidol.ac.th (P.F.); rachatawan.lee@mahidol.ac.th (R.L.) \\ 4 Maxillofacial Prosthetic Unit, Department of Prosthodontics, Faculty of Dentistry, Mahidol University, \\ 6 Yothi Street, Ratchathewi District, Bangkok 10400, Thailand; binit.shr@mahidol.ac.th \\ * Correspondence: boworn.klo@mahidol.ac.th; Tel.: +66-22007845-6 or +66-816848266
}

\section{check for} updates

Citation: Klongnoi, B.; Sresumatchai, V.; Khovidhunkit, S.-o.P.;

Fuangtharnthip, P.; Leelarungsun, R.; Shrestha, B. Pilot Model for

Community Based Oral Cancer

Screening Program: Outcome from 4 Northeastern Provinces in Thailand. Int. J. Environ. Res. Public Health 2021, 18, 9390. https://doi.org/10.3390/ ijerph18179390

Academic Editor: Yuji Kabasawa

Received: 11 August 2021

Accepted: 31 August 2021

Published: 6 September 2021

Publisher's Note: MDPI stays neutral with regard to jurisdictional claims in published maps and institutional affiliations.

Copyright: (c) 2021 by the authors. Licensee MDPI, Basel, Switzerland. This article is an open access article distributed under the terms and conditions of the Creative Commons Attribution (CC BY) license (https:// creativecommons.org/licenses/by/ $4.0 /)$.

\begin{abstract}
Management of advanced-stage oral cancer adds a great burden to individuals and health care systems. Community-based oral cancer screening can be beneficial in early detection and treatment. In this study, a novel oral cancer screening program was conducted utilizing an existing network of health care personnel, facilities, and digital database management for efficient coverage of a large population. The screening program considered 392,396 individuals aged $\geq 40$ from four northeastern provinces in Thailand. Three levels of screening were performed: S1 by village healthcare volunteers to identify risk groups, S2 by dental auxiliaries to visually identify abnormal oral lesions, and S3 by dentists for final diagnosis and management. A total of 349,318 individuals were interviewed for S1, and 192,688 were identified as a risk group. For S2, 88,201 individuals appeared, and 2969 were further referred. Out of 1779 individuals who appeared for S3, oral potentially malignant disorders (OPMDs) were identified in 544, non-OPMDs in 1047, doubtful lesions in 52, and no results in 136 individuals. Final treatment was carried out in 704 individuals that included biopsies of 504 lesions, exhibiting 25 cancerous lesions and 298 OPMDs. This study is so far one of the largest oral cancer screening programs conducted in Thailand and showed effective implementation of community-based oral cancer screening.
\end{abstract}

Keywords: community screening; oral cancer; oral potentially malignant disorders; village health volunteers; cancer screening

\section{Introduction}

Oral cancer is the sixth most prevalent cancer in the world [1], and accounted for an estimated 350,000 new cases and 177,000 deaths in 2018 [2]. Thailand is a country in Southeast Asia comprising 77 provinces that are arranged over five distinct geographical regions-Northeast, North, West, Central, and South (Figure 1). Oral cancer was reported as the eighth most leading form of cancer in Thai men and accounted for an ASR incidence of 4.6 and 3.2 cases per 100,000 males and females, respectively [3]. A 2018 Thai multicenter histopathological study reported squamous cell carcinoma as the most prevalent lesion $(67 \%)$ [4]. It is estimated that by 2040 the incidence of lip and oral cavity cancer will increase by almost $65 \%$ from the current estimates [5]. 


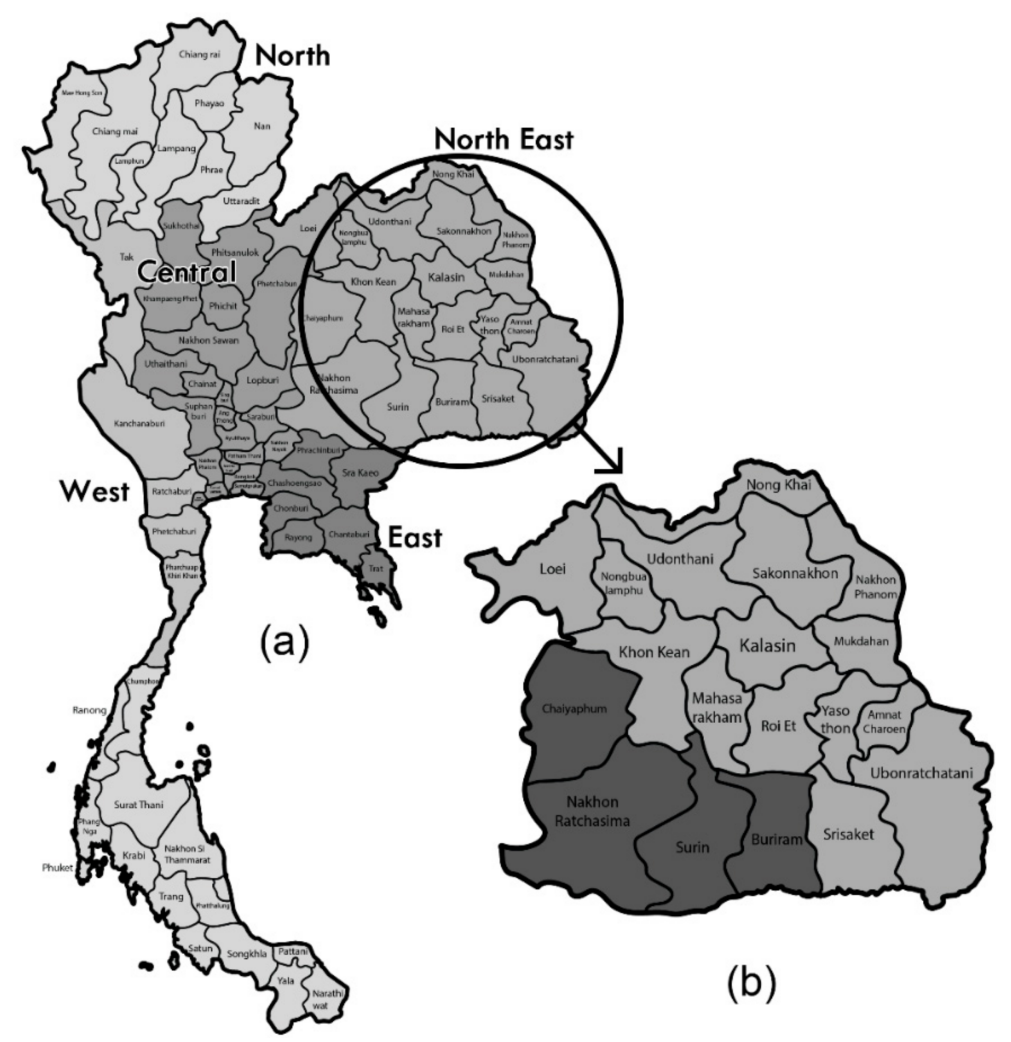

Figure 1. (a) Geographic map of Thailand; (b) northeastern provinces of Thailand with provinces considered for this study shaded dark.

Oral cancer is considered a lifestyle disease. Behaviors such as alcohol consumption and smoking have been primarily associated with increased risk of oral cancer. Exposure to human papillomavirus (HPV), syphilis, oro-dental factors, dietary deficiencies, chronic candidiasis, and viruses are also important predisposing factors [6]. Although globally declining in trend, the traditional habit of betel nut chewing is still prevalent in many parts of Thailand and has been known to contribute to the risk [7]. In the low socioeconomic population, knowledge and awareness of oral health may be limited, which may be further exasperated by the rural setting where timely diagnosis and treatment may be restricted due to lack of easily accessible health care service providers and facilities.

Early detection of oral cancer is important as diagnosis at late stages would significantly increase the treatment cost and associated morbidity and mortality rates. In several previous reports, more than half of the oral carcinomas were diagnosed at late stages (TNM Stages III and IV) [8-10]. A retrospective analysis of the Cancer Registry of Maharaj Nakorn Chiang Mai Hospital, Thailand, showed a higher predilection towards late diagnosis of oral squamous cell carcinoma, especially in patients aged $\geq 40$. Only $3 / 8$ of the confirmed diagnoses occurred at Stage I or II, whereas 5/8 occurred at Stage III or IV [11]. Similarly, a cohort study of 88 patients identified the male gender as a risk factor for late-stage diagnosis with strong associations with advanced stages and moderate-poor differentiation [9]. Late detection can also be attributed to the asymptomatic nature of the disease, especially during its early stages. Even when symptoms arise, patients may delay seeking medical consultation, which can further complicate the treatment [12]. From the population-based cancer registry of Khon Kaen Province, the five-year survival rate of oral cancer was reported as $64.9 \%$ for Stage I and 13\% for Stage IV [13]. Therefore, initiatives for cancer prevention, especially early detection and intervention, are important to lessen cancer-related burdens on individuals and society.

Various forms of oral cancer screening and prevention have been described in the literature [14,15]. Screening of the general population for oral cancer is considered less effective due to its low incidence. Oral cancer screening programs that are designed for 
large populations mostly focus on primary prevention and on identifying individuals with high-risk behaviors in the general population. However, due to the cost involved, only a few nations have been able to implement it as a part of their general health screening program.

In Thailand, several studies have been conducted on oral cancer screening [16,17], but most of them have been based on small populations. Therefore, in this study, a novel community-based multi-level oral cancer screening program was carried out on a large population. The screening was designed for efficient utilization of the country's existing network of heath care workers and facilities in conjunction with a digital patient registry. This pilot study focused on the screening of a randomized cluster of population from four provinces in Northeastern Thailand, and the results of the screening program have been reported.

\section{Materials and Methods}

This study was conducted from August 2019-June 2021. Population data for the study were obtained from an existing digital patient registry database provided by the Ministry of Public Health, Thailand (HosXP), and included individuals who were $\geq 40$ years old and residing in Buriram, Chaiyaphum, Nakhorn-Ratchasima, and Surin provinces (Figure 1). Prior to the study, consultations and dialogues with the local administration were carried out at sub-district/district levels regarding the objectives of the screening program, and approvals were sought from the local community. Local village healthcare volunteers (VHVs) were assigned according to their corresponding villages. The first "S1" screening was performed by the VHVs to analyze individuals' risk behaviors and was carried out at individuals' homes. After attaining their consent, population demographics were attained along with an objective questionnaire-based interview to assess their risk behaviors. The risk factors were categorized into 8 parts as follows - current or past history of (a) smoking, (b) chewing tobacco or snuffing, (c) alcohol consumption, (d) betel quid consumption, (e) long durations of sun exposure while working, (f) denture wear for $>1$ year, $(\mathrm{g})$ irritation of oral mucosa, and/or (h) history of head and neck cancer.

Individuals with $\geq 1$ positive factor were deemed a risk group and referred for visual examination by trained dental auxiliaries at "S2" screening at sub-district level hospitals. These dental auxiliaries had received prior formal education on dental hygiene and were well capable of carrying out minor dental procedures. Prior to the study, they also received training by specialists in oral medicine. During S2 screening, they carried out thorough visual examination of the oral cavity with standardized instruments under light illumination for signs of abnormalities and the presence of red or white lesions using a standardized form provided by the study.

In the presence of suspicious or uncertain lesions, referrals were made to dentists at district-level hospitals for further investigation. At "S3" screening, dentists carried out the necessary intra- and extra-oral examinations, including palpation of lymph nodes and radiographic and histopathologic investigations, as deemed necessary. All relevant findings along with the treatment records were added to the digital registry.

Oral potentially malignant disorder (OPMD) lesions were categorized as oral leukoplakia, erythroplakia, oral submucosal fibrosis, erythroleukoplakia, and verrucous hyperplasia [18], whereas non-OPMD lesions included fibrous hyperplasia, irritating fibroma, pyogenic granuloma, etc. For both OPMD and non-OPMD lesions, primary treatment included medication, laser therapy, removal of irritation, and minor surgeries. Individuals with cancerous lesions were then referred to provincial hospitals for necessary management. Individuals with OPMDs were followed up at the S3 level, where they were recalled every 6 months for continual examination. Individuals with non-OPMD lesions, no lesions, or without a confirmatory diagnosis were referred to the S2 level for regular follow-up (Figure 2). To aid in patient database registry and management, a customized software module designed by the oral cancer screening program was added to the existing HosXP program. The program allowed data entry and retrieval regarding the risk factors recorded 
from S1 and S2 levels, characteristics of the lesions found in S2 and S3 levels, and the treatment received by each patient at the $\mathrm{S} 3$ level.

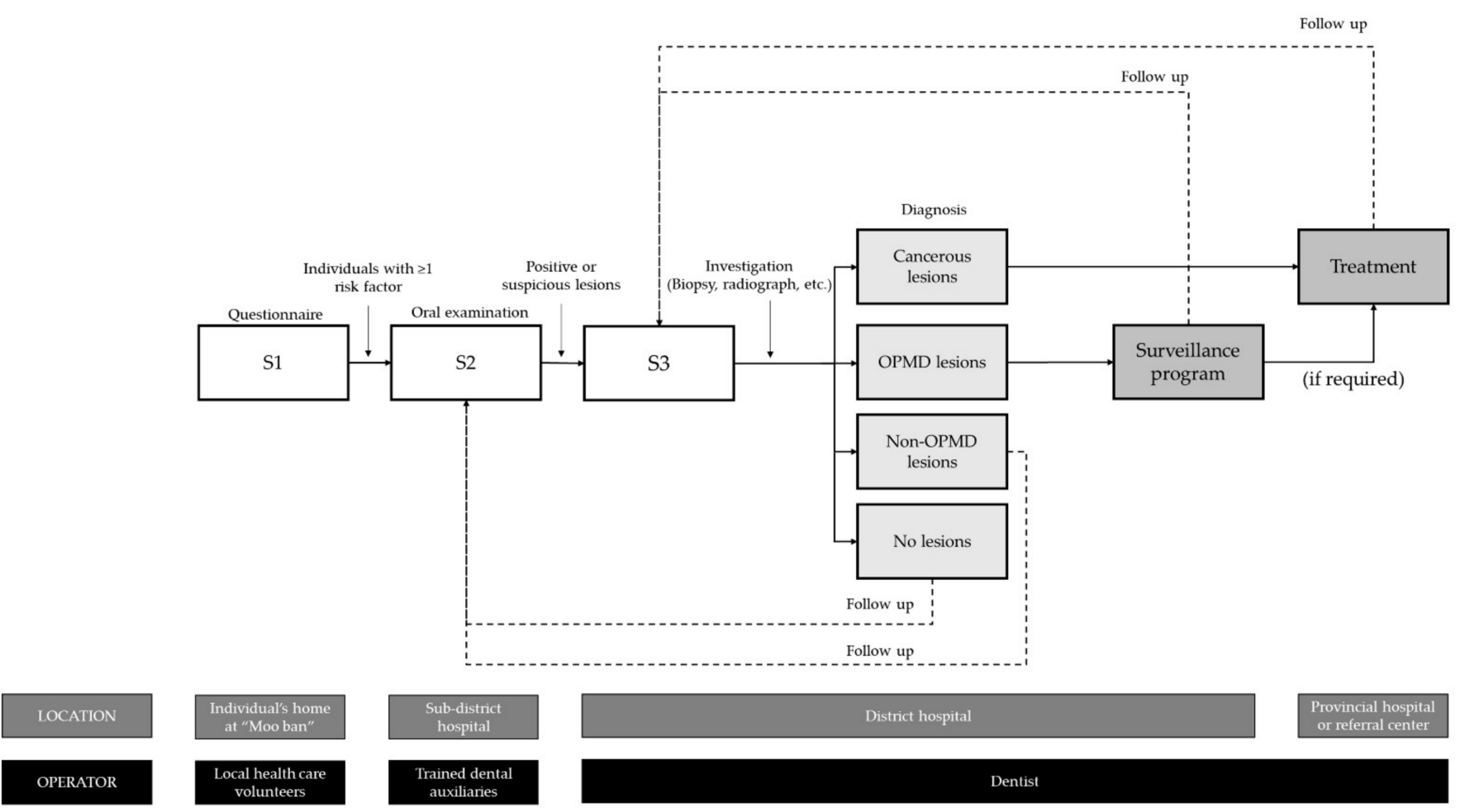

Figure 2. Screening methodology used in this study. OPMD = Oral potentially malignant disorder.

\section{Results}

The study took into consideration a target population of 392,396 individuals from a total of 81 sub-districts from 13 districts of 4 provinces. A total of 26,921 VHVs were mobilized for the study with an average target population, with a healthcare volunteer ratio of 15:1 (Table 1). Out of the total target population, 349,318 enrolled in the study for S1 screening (Figure 3).

Table 1. Demographics of each district considered for the study.

\begin{tabular}{|c|c|c|c|c|c|}
\hline Province & District & Total Population & $\begin{array}{l}\text { Target Population } \\
\text { Aged } \geq 40\end{array}$ & No. of VHVs & $\begin{array}{c}\text { Target Population: } \\
\text { VHVs }\end{array}$ \\
\hline \multirow{6}{*}{ Nakhorn-Ratchasima } & Non Sung & 85,091 & 48,470 & 2565 & 19 \\
\hline & Prathai & 71,433 & 29,555 & 1703 & 17 \\
\hline & Kaam Thale So & 25,902 & 8491 & 774 & 11 \\
\hline & Pra Thong Kham & 36,688 & 14,175 & 1041 & 14 \\
\hline & Non Thai & 54,699 & 26,396 & 1803 & 15 \\
\hline & $\begin{array}{l}\text { Mueang Nakhon } \\
\text { Ratchasima }\end{array}$ & 232,838 & 76,598 & 8107 & 9 \\
\hline \multirow{2}{*}{ Buriram } & Lahan Sai & 19,463 & 24,714 & 1319 & 19 \\
\hline & Krasang & 101,637 & 32,232 & 1663 & 19 \\
\hline \multirow{2}{*}{ Surin } & Si Narong & 46,803 & 13,589 & 832 & 16 \\
\hline & Khwao Sinarin & 34,361 & 12,653 & 748 & 17 \\
\hline \multirow{3}{*}{ Chaiyaphum } & Phu Khiao & 108,678 & 49,399 & 2935 & 17 \\
\hline & Kaeng Khro & 72,820 & 35,691 & 1848 & 19 \\
\hline & Bamnet Narong & 40,671 & 20,433 & 1583 & 13 \\
\hline Total & & 931,084 & 392,396 & 26,921 & 15 (mean ratio) \\
\hline
\end{tabular}

VHV = Village healthcare volunteers. 


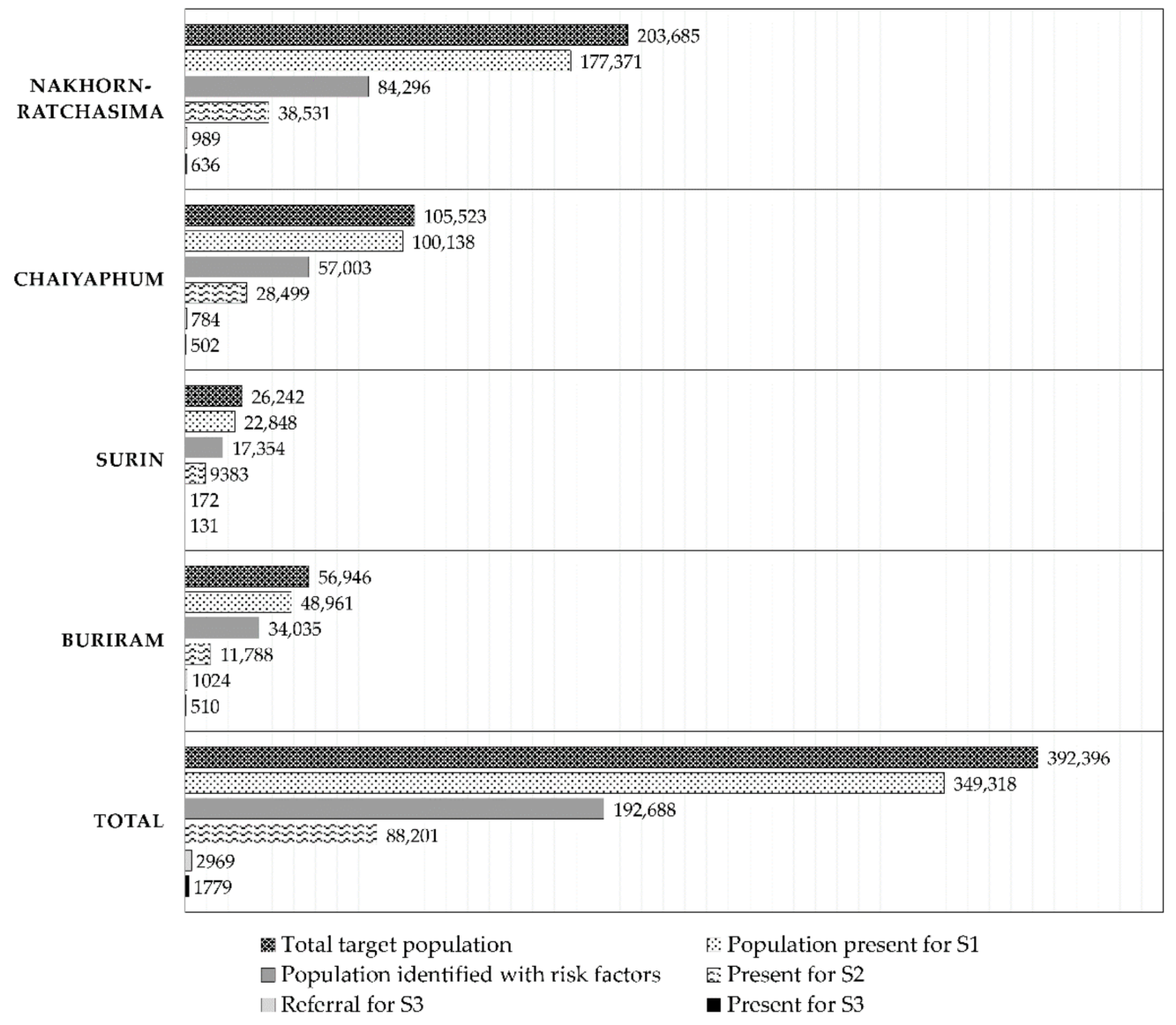

Figure 3. Results of screenings 1-3 in this study.

From them, 192,688 individuals were identified as the risk group and comprised approximately half of the individuals screened for S1. The results of the analysis of the risk factors prevalent among the individuals present in S1 screening were as shown in Figure 4. The most prevalent risk factor in this population was alcohol consumption $(33.8 \%)$, followed by smoking $(23.2 \%)$, betel quid consumption $(16.3 \%)$, long duration of sun exposure $(12.7 \%)$, denture wear $>1$ year $(6.6 \%)$, chewing tobacco or snuffing $(4.7 \%)$, history of oral cancer $(2.6 \%)$, and irritation of oral mucosa (1.2\%). All four provinces had smoking prevalent in $>20 \%$ of the study population, except Nakhon Ratchasima and Surin, which exhibited a prevalence rate of $24.6 \%$. Alcohol consumption was most prevalent in Chaiyapum at $39.4 \%$, followed by Surin at $34.2 \%$. Betel quid consumption was evenly present in all provinces with a prevalence rate of approximately $15 \%$, except Chaiyaphum at $17.2 \%$. On the other hand, long duration of exposure to the sun was the highest in the study population from Buriram at approximately $20 \%$. The overall prevalence of chewing tobacco or snuffing was $4.7 \%$, whereas the prevalence of denture wear, irritation of oral mucosa, and history of oral cancer was $6.6 \%, 1.2 \%$, and $2.6 \%$, respectively. 


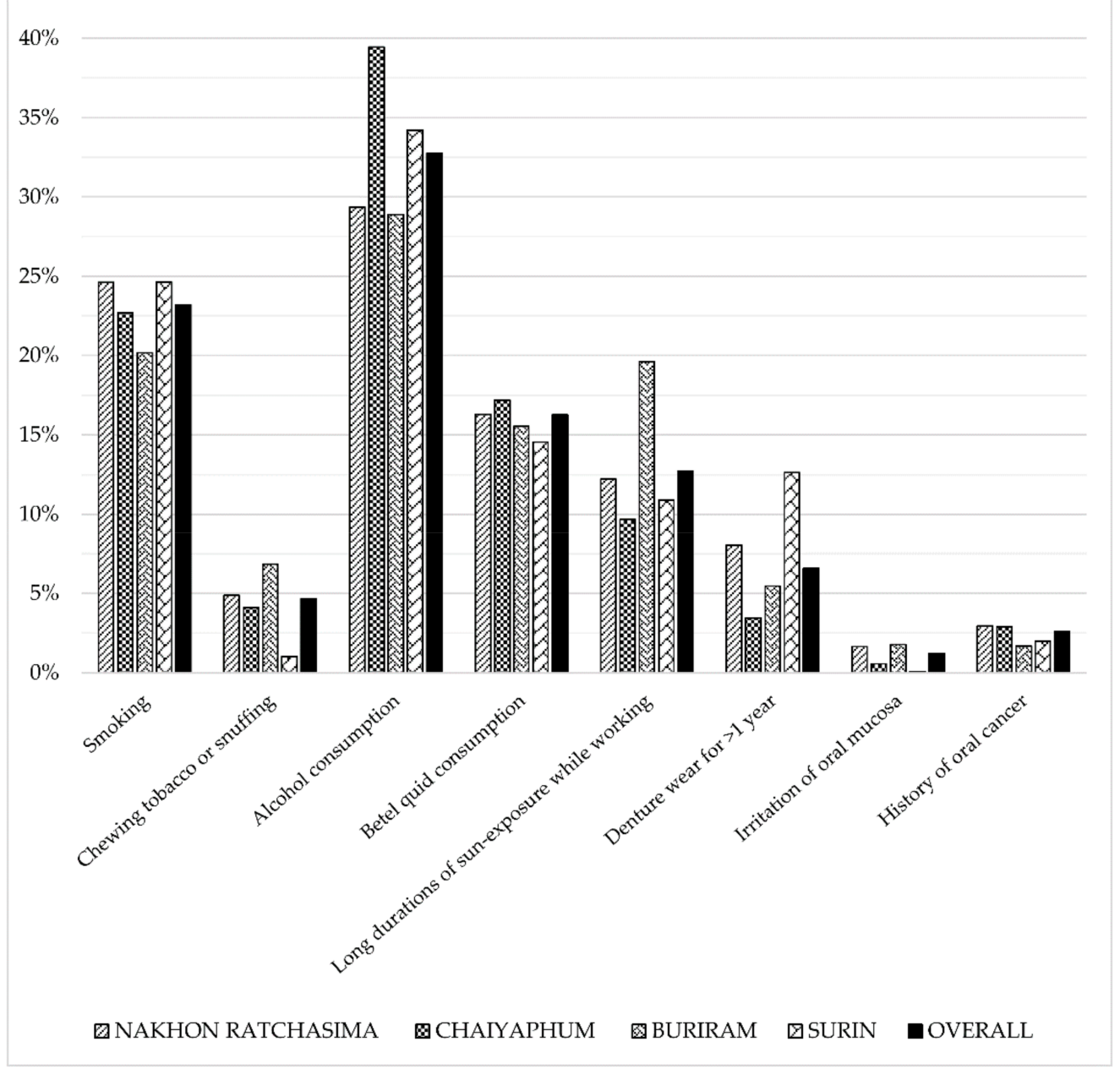

Figure 4. Prevalence of risk factors in individuals present at S1.

In S2-level screening at local sub-district health centers, 88,201 individuals participated with a dropout rate of $45.8 \%$ from S1. From this population, a total of 2969 individuals with abnormal or doubtful lesions were identified and further referred for S3-level screening (Figure 3). For S3 screening, 1779 individuals participated with a dropout rate of $40 \%$. Out of them, 544 were diagnosed with OPMDs, 1047 with non-OPMDs, and 52 with doubtful lesions, and 136 had no diagnosis (Table 2). From them, 704 were treated, which included 504 biopsies that exhibited 25 cancerous lesions, 298 OPMDs, and 181 nonOPMDs, as shown in Table 3. The biopsy results showed confirmatory diagnosis of squamous cell carcinoma in $14(56 \%)$ lesions, which were obtained from 12 individuals (mean age of 66.8 years, age range 50-95), and verrucous carcinoma in $6(24 \%)$ lesions. The histopathological reports of the cancerous lesions along with patient demographics are summarized in Table 4 . The majority of the OPMDs comprised mild epithelial dysplasia $(45 \%)$, oral lichen/lichenoid planus (21\%), and moderate epithelial dysplasia $(13.5 \%)$ as shown in Table S1, whereas non-OPMDs comprised fibroepithelial hyperplasia (42\%), squamous papilloma (10.5\%), and giant cell fibroma ( $8 \%$ ) as shown in Table S2. 
Table 2. Results of individuals diagnosed and treated at the S3 level.

\begin{tabular}{|c|c|c|c|c|c|c|c|}
\hline \multirow[b]{2}{*}{ Province } & \multicolumn{5}{|c|}{ Diagnosis } & \multicolumn{2}{|c|}{ Treatment } \\
\hline & OPMDs & Non-OPMDs & Doubtful & No Diagnosis & Observed & Treated $^{1}$ & $\begin{array}{c}\text { Biopsy in } \\
\text { Treated Group }\end{array}$ \\
\hline $\begin{array}{c}\text { Nakhorn- } \\
\text { Ratchasima }\end{array}$ & 156 & 438 & 15 & 27 & 316 & 199 & 180 \\
\hline Buriram & 213 & 238 & 13 & 46 & 183 & 275 & 166 \\
\hline Surin & 53 & 49 & 1 & 28 & 45 & 55 & 48 \\
\hline Chaiyaphum & 122 & 322 & 23 & 35 & 201 & 175 & 110 \\
\hline Total & 544 & 1047 & 52 & 136 & 745 & 704 & 504 \\
\hline
\end{tabular}

${ }^{1}$ Treatment included medication, biopsy, laser therapy, removal of irritation, or minor surgery.

Table 3. Results of biopsies (number of lesions).

\begin{tabular}{ccccc}
\hline Province & $\begin{array}{c}\text { Cancerous } \\
\text { Lesions }\end{array}$ & OPMDs & Non-OPMDs & Total \\
\hline Nakhorn-Ratchasima & 12 & 87 & 81 & 180 \\
Buriram & 7 & 100 & 59 & 166 \\
Surin & 3 & 34 & 11 & 48 \\
Chaiyaphum & 3 & 77 & 30 & 110 \\
Total & 25 & 298 & 181 & 504 \\
\hline
\end{tabular}

Table 4. Histopathological report of cancerous lesions with patient demographics.

\begin{tabular}{|c|c|c|c|c|c|}
\hline Lesion Number & Gender & Age & Diagnosis & Type & Location \\
\hline 1 & M & 64 & SCC & Micro invasive & Buccal mucosa \\
\hline 2 & $\mathrm{~F}$ & 70 & $\begin{array}{c}\text { VCC versus verrucous } \\
\text { hyperplasia }\end{array}$ & & Buccal mucosa \\
\hline 3 & F & 73 & $\begin{array}{l}\text { Clear cell odontogenic } \\
\text { carcinoma }\end{array}$ & & Palatal gingiva \\
\hline 4 & $\mathrm{~F}$ & 54 & Mucoepidermoid carcinoma & Low grade & Retromolar area \\
\hline 5 & $\mathrm{~F}$ & 50 & Basal cell carcinoma & & Nose \\
\hline 6 & $\mathrm{~F}$ & 80 & Adenoid cystic carcinoma & & Lower lip \\
\hline 7 & M & 55 & Lymphoma & & Palatal mucosa \\
\hline 8 & $\mathrm{~F}$ & 86 & VCC & & Retromolar area \\
\hline 9 & \multirow[b]{2}{*}{ M } & \multirow[b]{2}{*}{67} & SCC & WD & Lower lip \\
\hline 10 & & & SCC & NS & Right vermillion border \\
\hline 11 & M & 65 & SCC & Micro invasive & $\begin{array}{l}\text { Ventral border of tongue, floor } \\
\text { of mouth }\end{array}$ \\
\hline 12 & M & 56 & SCC & WD & Retromolar area \\
\hline 13 & $\mathrm{M}$ & 59 & SCC & NS & Lateral tongue \\
\hline 14 & M & 71 & VCC & & Buccal mucosa \\
\hline 15 & $\mathrm{~F}$ & 73 & SCC & WD & Lower lip \\
\hline 16 & $\mathrm{~F}$ & 95 & SCC & NS & Lower lip \\
\hline 17 & M & 86 & SCC & Micro invasive & Lower lip \\
\hline 18 & M & 89 & SCC & WD & Soft palate, uvula \\
\hline 19 & \multirow{3}{*}{$\mathrm{F}$} & \multirow{3}{*}{79} & VCC & & Upper lip \\
\hline 20 & & & VCC & & Upper gums \\
\hline 21 & & & VCC & & Lower lip \\
\hline 22 & M & 69 & SCC & NS & Lateral Tongue \\
\hline 23 & $\mathrm{~F}$ & 76 & SCC & NS & Palate \\
\hline 24 & \multirow[b]{2}{*}{$\mathrm{F}$} & \multirow{2}{*}{76} & SCC & WD & Lower lip \\
\hline 25 & & & SCC & WD & Upper lip \\
\hline
\end{tabular}

SCC = squamous cell carcinoma, VCC = verrucous cell carcinoma, $\mathrm{WD}=$ well-differentiated, $\mathrm{NS}=$ not specified. 


\section{Discussion}

The northeastern region of Thailand comprises 20 provinces with a total population of 22,240,574 (2018). This pilot study focused on four neighboring provinces and included a total of 13 districts with a cumulative population of 931,084 individuals. The target population aged $\geq 40$ accounted for $42 \%(392,824)$ of this population. The WHO (2011) reported that the overall prevalence rate of smokers among the general Thai adult population was $24 \%$, with a higher prevalence in rural areas and among males. On the contrary, the use of smokeless tobacco was more prevalent in females. Considering the regional data, the overall prevalence of tobacco use in the northeastern region was second only to the southern region [19].

The association between oral cancer and tobacco smoking, alcohol consumption, and betel quid chewing has been well established [20]. Betel quid is traditionally prepared by wrapping areca nut with fresh or fermented betel leaf with lime, tobacco, or other regional additives [21]. Although primarily consumed for its psychostimulant properties, reca alkaloids (arecoline and arecaidine) present in areca nut can be a major source of toxicity [7]. Betel nut consumption and smoking was reported to increase the risk of developing oral premalignant lesion by eight- to nine-fold than those who refrained [16]. Most of the individuals in the northeastern region of Thailand rely on agriculture for their livelihood and are exposed to prolonged durations of sunlight, increasing their overall risk of cancer [22]. Alcohol consumption, smoking, betel quid consumption, and long durations of sun exposure were the most prevalent risk factors among the individuals who appeared for the initial S1 screening in our study. These data also agreed with a previous report by the National Statistics Office, which reported a prevalence rate of $21.1 \%$ for smoking and $32.8 \%$ for alcohol consumption in the northeastern region [23]. Similarly, a survey on the use of smokeless tobacco in Thailand reported that the prevalence rate of betel quid consumption was the highest in rural communities and in the age group $>65$ years at $8.2 \%$ compared to other age groups. Comparatively, a higher prevalence of betel quid consumption $(16.3 \%)$ and the use of chewing tobacco or snuffing $(4.7 \%)$ was observed in our results, which could have been due to the region and age group-specific nature of the study. Furthermore, both past and current users or experiences were grouped as one in our analysis of the risk factors. In general, the prevalence of smokeless tobacco consumption in Thailand remains low (3.2\%) compared to other countries such as Bangladesh (27.2\%) and India $(25.9 \%)$ [24].

The screening of a large group of individuals for early detection of oral cancer can be challenging due to the required resources, capable personnel, and facilities. Opportunistic screening of oral cancer can be performed when individuals visit dental professionals. This method of screening is considered cost effective to identify potential lesions [25]; however, in developing countries the number of individuals who regularly visit dental clinics is low, and it is still questionable whether these individuals represent the general population. Self-examination of the oral mucosa by the individuals themselves may prove difficult, as they may not be able to differentiate between normal and abnormal mucosa without appropriate education or visual media [26]. Therefore, to improve the overall effectiveness of this study, we first considered identifying high-risk individuals from the general population and then visually screening them for abnormalities.

Several large-population-based oral cancer screening programs have been conducted with various levels of success. In a study carried out in Gujrat, India, 5214 trained village healthcare workers screened 2,610,423 individuals and referred 3309 individuals to tertiary care centers, among which 1890 (57.1\%) were diagnosed positive for malignancy [27]. Similarly, in a study conducted in Kannur, Kerala, 1,061,088 individuals were surveyed by 6325 volunteers who identified 3226 patients, out of which 2507 attended subsequent screenings, and 13 were identified with oral cancer and 174 with precancerous lesions [28]. A study by Chuang et al. followed up with individuals with habits of smoking and betel quid chewing in Taiwan. A questionnaire-based interview was followed up by visual examination by trained dentists. Out of 2,334,299 individuals who took part in the study, 
16,494 were identified with suspicious lesions, among which 11,051 were identified with premalignant lesions and 4110 were identified with oral cancer. Subsequent evaluations during follow-up led to the identification of an additional 3923 lesions [29]. Besides initial screening, subsequent follow-ups of individuals, especially those with potentially pre-malignant lesions, play a pivotal role in the success of oral cancer studies.

Thailand has an existing extensive network of 800,000 (2012) [30] active VHVs, who are overseen by the Department of Health Service Support to provide basic health-related information at the local grassroots level. Many of them can speak local dialects and can encourage villagers to seek medical consultation through discussion and informal conversations. One such achievement attained by the VHVs in this study was a high compliance from the target population into S1 (89\%). Unfortunately, at each level of screening dropouts were observed: S1 to S2 $-54 \%$ and S2 to S3-40\%. This could have been due to the rural backdrop, where individuals cannot spare their daily wage or traveling time to visit a distant healthcare facility for health issues that may not be of importance to them. At the final S3 screening, 704 individuals were treated and 745 were placed under observation. Biopsy results revealed 25 cancerous lesions in 21 individuals and 298 OPMD lesions. Although the cancer lesions were mostly prevalent in the fifth to eighth decade of life, one third occurred in the seventh decade, which was in conjunction with a previous multicenter histopathological study of oral malignant lesions [4].

This has been so far the largest documented observation of malignant and premalignant lesions in Thailand. In a similar community-based oral cancer study carried out in five districts of Roi-et province in Thailand, 57,763 adults were sent self-screening forms and questionnaires, out of which 3428 responded positively and were subsequently examined by dental nurses. Only 201 out of 407 who were referred appeared for their appointment with dentists. Ninety-nine patients were then referred to an oral and maxillofacial surgeon at a provincial hospital. Although 88 appeared, only 10 individuals accepted biopsy, and the results showed 1 cancerous lesion and 6 PMDs [17]. Compared to the Roi-et study, this study utilized a three-tier screening process, which improved the workflow by reducing redundant steps both for the patient and treatment team. It allowed the hospitals and dentists to focus on diagnosis and treatment rather than screening. Treatments such as medication, biopsy, laser therapy, removal of irritation, and minor surgery were performed at district hospitals with visiting treatment teams from central or regional hospitals, which also created opportunities for learning, collaboration, and knowledge sharing among the teams. Only patients with advanced cancerous lesions were referred for proper treatment at the central or regional hospital.

Cost utility analysis compares the cost of an intervention to its effectiveness measured in natural health units. For an intervention to be cost effective, the cost of the intervention per disability-adjusted life year should be less than three times the country's annual gross domestic product (GDP) per capita [31]. In context with Thailand, a 2013 report established the ceiling threshold of cost effectiveness at THB 160,000 for each quality-adjusted life year (QALY) gained [32]. Similarly, Kumdee et al. calculated the costs of diagnosis, treatment, and follow-up of oral cancer patients at Roi et Hospital, Thailand, and attained an incremental cost-effective ratio (ICER) of THB 311,030 per QALY, which only had a 30\% probability of being cost effective compared to no-screening [33]. Our preliminary findings on the cost effectiveness, attained in terms of QALYs calculated by multiplying the life expectancy by utility value, attained an ICER of THB 135,314.30, which was 0.53 times the current GDP of Thailand (USD 7804.74, 1 USD = THB 32.84). These results are indicative of a highly effective intervention, and a detailed report is in progress.

For future implementation, it is suggested to adjust the criteria for S1 screening for efficient identification of high-risk individuals from the others and to lessen the workload on S2-level screening. One method of attaining effective recruitment would be to segregate the risk factors into major and minor risk factors, and to only recruit individuals with risk factors that have the highest association with oral cancer and OPMDs, such as alcohol consumption, tobacco smoking, use of smokeless tobacco, and betel quid chewing. 
Exposure to multiple risk factors can also be considered during recruitment into S2, as synergistic effects among risk factors were observed in our previous study [34]. These changes in recruitment could further improve the study's cost effectiveness and reduce potential dropouts.

The digital patient registry also simplified tracking individuals' progress from the S1 to S3 level. Although the accessibility of the system was greatly improved via internetenabled terminals, it was also prone to human error. At S3-level screening, 136 individuals were labeled under "no diagnosis" due to improper or lack of data entry. To improve the effectiveness of the study, data entry should be strictly implemented. Even though oral cancer screening by visual examination is considered to have high specificity and sensitivity [35], some potentially harmful lesions could have been missed at the S2 level. Moreover, the study identified 544 individuals with OPMDs, which showed the necessity for a robust follow-up system for early detection of malignant transformations. In order to reduce dropouts and to improve the compliance of patients under the surveillance program and follow-ups, an automated module is currently under development that would send digital text-based reminders (SMS) to the patients and treatment team regarding their appointments [36]. However, its results, comparisons to conventional telephone-based reminders, and implications are yet to be determined.

\section{Conclusions}

Our oral screening program aimed for complete management, where individuals with cancerous or premalignant lesions were screened, diagnosed, treated, and followed up with using standard protocols. The results of this pilot model have created one of the largest oral cancer databases in Thailand and showed that a community-based screening model utilizing VHVs, dental auxiliaries, and dentists with a digital database management could be effective in oral cancer screening of a large population. The model also has the potential to be applied for the screening of other forms of cancer. However, it may be best suited for countries with an existing network of health care workers and facilities.

Supplementary Materials: The following are available online at https:/ /www.mdpi.com/article/10 .3390/ijerph18179390/s1, Table S1: Histopathological report of OMPDs and their frequency, Table S2: Histopathological report of non-OPMDs and their frequency.

Author Contributions: Conceptualization, B.K.; methodology, B.K., S.-o.P.K. and V.S.; validation, B.K., S.-o.P.K. and V.S.; formal analysis, B.K., S.-o.P.K. and V.S.; investigation, B.K. and S.-o.P.K.; resources, B.K.; writing—original draft preparation, B.S., R.L. and P.F.; writing—review and editing, B.K., B.S., R.L., S.-o.P.K. and P.F.; project administration, B.K. All authors have read and agreed to the published version of the manuscript.

Funding: This study was funded by Mahidol University Fund number 051/2562. The APC was funded by the authors.

Institutional Review Board Statement: The study was conducted according to the guidelines of the Declaration of Helsinki, and approved by the Mahidol University Institutional Review Board, Faculty of Dentistry and Faculty of Pharmacy (COA.NO.MU-DT/PY-IRB 2019/041.0307).

Informed Consent Statement: Informed consent was obtained from all subjects involved in the study.

Data Availability Statement: Data can be made available on request by email.

Acknowledgments: The authors would like to thank Harin Clypuing, Prasan Tangjaturonrasme, and Angkana Wisutthajaree from Maharat Nakhon Ratchasima Hospital for their valuable contributions to the project. The authors would also like to sincerely thank all the village healthcare volunteers, dental auxiliaries, and dentists who took part in the study.

Conflicts of Interest: The authors declare no conflict of interest. The funders had no role in the design of the study; in the collection, analyses, or interpretation of data; in the writing of the manuscript, or in the decision to publish the results. 


\section{References}

1. Lo Nigro, C.; Denaro, N.; Merlotti, A.; Merlano, M. Head and neck cancer: Improving outcomes with a multidisciplinary approach. Cancer Manag. Res. 2017, 18, 363-371. [CrossRef]

2. Mummudi, N.; Agarwal, J.P.; Chatterjee, S.; Mallick, I.; Ghosh-Laskar, S. Oral cavity cancer in the Indian subcontinent-Challenges and opportunities. Clin. Oncol. 2019, 31, 520-528. [CrossRef]

3. Tangjaturonrasme, N.; Vatanasapt, P.; Bychkov, A. Epidemiology of head and neck cancer in Thailand. Asia Pac. J. Clin. Oncol. 2018, 14, 16-22. [CrossRef] [PubMed]

4. Dhanuthai, K.; Rojanawatsirivej, S.; Subarnbhesaj, A.; Thosaporn, W.; Kintarak, S. A multicenter study of oral malignant tumors from Thailand. J. Oral Maxillofac. Pathol. 2016, 20, 462-466. [CrossRef] [PubMed]

5. International Association of Cancer Registries GLOBOCAN. Available online: https:/ / gco.iarc.fr (accessed on 12 June 2020).

6. Ram, H.; Sarkar, J.; Kumar, H.; Konwar, R.; Bhatt, M.L.; Mohammad, S. Oral cancer: Risk factors and molecular pathogenesis. J. Maxillofac. Oral Surg. 2011, 10, 132-137. [CrossRef]

7. Chen, P.H.; Mahmood, Q.; Mariottini, G.L.; Chiang, T.A.; Lee, K.W. Adverse health effects of betel quid and the risk of oral and pharyngeal cancers. Biomed Res. Int. 2017, 2017, 3904098. [CrossRef] [PubMed]

8. McGurk, M.; Chan, C.; Jones, J.; O'regan, E.; Sherriff, M. Delay in diagnosis and its effect on outcome in head and neck cancer. Br. J. Oral Maxillofac. Surg. 2005, 43, 281-284. [CrossRef]

9. Seoane-Romero, J.M.; Vázquez-Mahía, I.; Seoane, J.; Varela-Centelles, P.; Tomás, I.; López-Cedrún, J.L. Factors related to late stage diagnosis of oral squamous cell carcinoma. Med. Oral Patol. Oral Cir. Bucal. 2012, 17, e35-e40. [CrossRef]

10. Onizawa, K.; Nishihara, K.; Yamagata, K.; Yusa, H.; Yanagawa, T.; Yoshida, H. Factors associated with diagnostic delay of oral squamous cell carcinoma. Oral Oncol. 2003, 39, 781-788. [CrossRef]

11. Komolmalai, N.; Chuachamsai, S.; Tantiwipawin, S.; Dejsuvan, S.; Buhngamongkol, P.; Wongvised, C.; Chitapanarux, I.; Iamaroon, A. Ten-year analysis of oral cancer focusing on young people in Northern Thailand. J. Oral Sci. 2015, 57, 327-334. [CrossRef]

12. McGurk, M.; Scott, S.E. The reality of identifying early oral cancer in the general dental practice. Br. Dent. J. 2010, 208, 347-351. [CrossRef]

13. Sungwalee, S.; Vatanasapt, P.; Suwanrungruang, K.; Promthet, S. Comparing survival of oral cancer patients before and after launching of the universal coverage scheme in Thailand. Asian Pac. J. Cancer Prev. 2016, 17, 3541-3544. [PubMed]

14. Ford, P.J.; Farah, C.S. Early detection and diagnosis of oral cancer: Strategies for improvement. J. Cancer Policy 2013, 1, e2-e7. [CrossRef]

15. Kujan, O.; Philip, S. Dilemmas of oral cancer screening: An update. Asian Pacific. J. Cancer Prev. 2013, 14, 3369-3373. [CrossRef]

16. Juntanong, N.; Siewchaisakul, P.; Bradshaw, P.; Vatanasapt, P.; Chen, S.L.; Yen, A.M.; Chen, T.S.; Promthet, S. Prevalence and factors associated with oral pre-malignant lesions in Northeast Thailand. Asian Pac. J. Cancer Prev. 2016, 17, 4175-4179.

17. Prasertsom, P.; Leela-adisorn, N.; Tangcharoendee, N.; Aroonpraphan, S. Prevalence and incidence of potential malignance disorder and oral cancer by organized community screening model in 5 districts of Roiet Province. Thai Dent. Public Health 2018, $23,46-54$.

18. Warnakulasuriya, S.; Kujan, O.; Aguirre-Urizar, J.M.; Bagan, J.V.; González-Moles, M.Á.; Kerr, A.R.; Lodi, G.; Mello, F.W.; Monteiro, L.; Ogden, G.R.; et al. Oral potentially malignant disorders: A consensus report from an international seminar on nomenclature and classification, convened by the WHO Collaborating Centre for Oral Cancer. Oral Dis. 2020. Online ahead of print. [CrossRef]

19. WHO Global Adult Tobacco Survey. Thailand Report 2011. Available online: https://www.who.int/tobacco/surveillance/ survey/gats/thailand_report_2011.pdf (accessed on 6 May 2020).

20. Loyha, K.; Vatanansapt, P.; Promthet, S.; Parkin, D.M. Risk factors for oral cancer in Northeast Thailand. Asian Pac. J. Cancer Prev. 2012, 13, 5087-5090. [CrossRef] [PubMed]

21. Recihart, P.A. Oral cancer and precancer related to betel and miang chewing in Thailand: A review. J. Oral Pathol. Med. 1995, 24, 241-243. [CrossRef]

22. Chen, Y.C.; Christiani, D.C.; Su, H.J.; Hsueh, Y.M.; Smith, T.J.; Ryan, L.M.; Chao, S.; Lee, J.Y.; Guo, Y.L. Early-life or lifetime sun exposure, sun reaction, and the risk of squamous cell carcinoma in an Asian population. Cancer Causes Control 2010, 21, 771-776. [CrossRef]

23. Statistical Forecasting Division, National Statistical Office, Bangkok. The Smoking and Drinking Behavior Study 2017. Available online: http:/ / www.nso.go.th/sites/2014en/Survey/social/health/SmokingDrinking/2017/Full\%20Report.pdf (accessed on 8 August 2021).

24. Sinha, D.N.; Gupta, P.C.; Ray, C.S. Prevalence of smokeless tobacco use among adults in WHO South-East Asia. Indian J. Cancer 2012, 49, 342-346. [CrossRef] [PubMed]

25. Lim, K.; Moles, D.R.; Downer, M.C.; Speight, P.M. Opportunistic screening for oral cancer and precancer in general dental practice: Results of a demonstration study. Br. Dent. J. 2003, 194, 497-502. [CrossRef] [PubMed]

26. Jornet, P.L.; Garcia, F.J.; Berdugo, M.L.; Perez, F.P.; Lopez, A.P. Mouth self-examination in a population at risk of oral cancer. Aust. Dent. J. 2015, 60, 59-64. [CrossRef] [PubMed]

27. Mishra, G.S.; Bhatt, S.H. Novel program of using village health workers in early detection and awareness of head and neck cancers: Audit of a community screening program. Indian J. Otolaryngol. Head Neck Surg. 2017, 69, 488-493. [CrossRef] [PubMed] 
28. Philip, P.M.; Nayak, P.; Philip, S.; Parambil, N.A.; Duraisamy, K.; Balasubramanian, S. Population-based cancer screening through community participation: Outcome of a district wide oral cancer screening program from rural Kannur, Kerala, India. South Asian J. Cancer 2018, 7, 244-248. [CrossRef]

29. Chuang, S.L.; Su, W.W.; Chen, S.L.; Yen, A.M.; Wang, C.P.; Fann, J.C.; Chiu, S.Y.; Lee, Y.C.; Chiu, H.M.; Chang, D.C.; et al Population-based screening program for reducing oral cancer mortality in 2,334,299 Taiwanese cigarette smokers and/or betel quid chewers. Cancer 2017, 123, 1597-1609. [CrossRef]

30. Kowitt, S.D.; Emmerling, D.; Fisher, E.B.; Tanasugarn, C. Community health workers as agents of health promotion: Analyzing Thailand's village health volunteer program. J. Community Health 2015, 40, 780-788. [CrossRef] [PubMed]

31. Marseille, E.; Larson, B.; Kazi, D.S.; Kahn, J.G.; Rosen, S. Thresholds for the cost-effectiveness of interventions: Alternative approaches. Bull World Health Organ. 2015, 93, 118-124. [CrossRef]

32. Thavorncharoensap, M.; Leelahavarong, M.; Doungthipsirkul, S.; Sompitak, S.; Teerawattananon, Y. Assessing a societal value for a ceiling threshold in Thailand; Health Intervention and Technology Assessment Program (HITAP), Ministry of Public Health: Nonthaburi, Thailand, 2013.

33. Kumdee, C.; Kulpeng, W.; Teerawattananon, Y. Cost-utility analysis of the screening program for early oral cancer detection in Thailand. PLoS ONE 2018, 13, e0207442. [CrossRef] [PubMed]

34. Worakhajit, P.; Fuangtharnthip, P.; Khovidhunkit, S.-o.P.; Chiewwit, P.; Klongnoi, B. The relationship of tobacco, alcohol, and betel quid with the formation of oral potentially malignant disorders: A community-based study from Northeastern Thailand Int. J. Environ. Res. Public Health 2021, 18, 8738. [CrossRef]

35. Mathew, B.; Sankaranarayanan, R.; Sunilkumar, K.B.; Kuruvila, B.; Pisani, P.; Nair, M.K. Reproducibility and validity of oral visual inspection by trained health workers in the detection of oral precancer and cancer. Br. J. Cancer 1997, 76, 390-394. [CrossRef] [PubMed]

36. Lin, $\mathrm{H}$.; $\mathrm{Wu}, \mathrm{X}$. Intervention strategies for improving patient adherence to follow-up in the era of mobile information technology: A systematic review and meta-analysis. PLoS ONE 2014, 9, e104266. [CrossRef] [PubMed] 